\title{
Evaluation Literacy: Perspectives of Internal Evaluators in Non-Government Organizations
}

\author{
Alison Rogers and Alicia McCoy \\ The University of Melbourne \\ Leanne M. Kelly \\ Deakin University, Geelong
}

\begin{abstract}
While there is an abundance of literature on evaluation use, there has been little discussion regarding internal evaluators' role in promoting evaluation use. Evaluation can be undervalued if context is not taken into consideration. Evaluation literacy is needed to make evaluation more appropriate, understandable, and accessible, particularly in non-government organizations (NGOs) where there is a growing focus on demonstrable outcomes. Evaluation literacy refers to an individual's understanding and knowledge of evaluation and is an essential component of embedding evaluation into organizational culture. In recognition of the value of the internal perspective, a small exploratory exercise was undertaken to reveal internal evaluator roles and ways of engaging with colleagues around evaluation. The exercise examined a key question: What is the role of evaluation literacy in internal evaluation in the non-government sector? Three Australian auto-narrative examples from internal evaluators highlight evaluation literacy and locate it among the multiplicity of roles required for optimal evaluation uptake. Analysis of the narratives revealed the underlying issues affecting evaluation use in NGOs and the skills needed to motivate and enable others to access, understand, and use evaluation information. Responding to the call for expanded research into internal evaluation from a practice perspective, the authors hope that the findings will stimulate a wider conversation and further advance understanding of evaluation literacy.
\end{abstract}

Keywords: evaluation, evaluation literacy, internal evaluation, non-government organization, not-for-profit

Resumé : Bien que les écrits sur l'utilisation de l'évaluation soient nombreux, il y a peu de discussion à propos du rôle que peuvent jouer les évaluateurs internes pour promouvoir l'utilisation de l'évaluation. La contribution de l'évaluation peut être sous-estimée si le contexte n'est pas pris en compte. Une certaine compréhension de l'évaluation est nécessaire pour la rendre pertinente et accessible, particulièrement dans les organisations non gouvernementales (ONG) où l'on accorde de plus en plus d'importance aux résultats mesurables. La connaissance

Corresponding author: Alison Rogers, Centre for Program Evaluation, The University of Melbourne, 100 Leicester Street, Melbourne, VIC 3010, Australia; arogers1@student.unimelb. edu.au

๑ 2019 Canadian Journal of Program Evaluation / La Revue canadienne d'évaluation de programme 34.1 (Spring / printemps), 1-20 doi: 10.3138/cjpe.42190 
de l'évaluation chez les utilisateurs privilégiés constitue un élément essentiel de l'intégration de lévaluation dans la culture organisationnelle. Notre étude porte sur le rôle des évaluateurs internes en matière de développement des connaissances et compétences évaluatives des acteurs organisationnels. À partir de trois exemples tirés de notre expérience comme évaluateurs internes, nous soulignons l'importance des connaissances en évaluation et leur rôle pour une utilisation optimale de l'évaluation. L'analyse des trois récits révèle les problèmes sous-jacents liés à l'utilisation de lévaluation dans les ONG ainsi que les compétences nécessaires pour motiver et permettre aux acteurs organisationnels d'accéder, de comprendre et d'utiliser les informations issues de l'évaluation. Nous espérons que les résultats stimuleront une conversation plus large et permettront de mieux comprendre cet enjeu important.

Mots clés : évaluation, littératie en matière d'évaluation, évaluateur interne, évaluatrice interne, organisation non gouvernementale, sans but lucratif

The need for evaluation literacy in non-government organizations (NGOs) is accelerating with a growing focus on demonstrable outcomes (McCoy, Rose, \& Connolly, 2014). Many NGOs depend on multiple grants from insecure funding streams with short-term cycles and need to produce evidence of their performance for multiple audiences (Braverman, 2013; Lee \& Nowell, 2015). Disconnects between funders' reporting demands and internal models of practice occur as staff are predominantly focused on service delivery, improving operations and accountability to beneficiaries (Campbell, Lambright, \& Bronstein, 2012; King \& Volkov, 2005; Naccarella et al., 2007). However, demonstrating accountability for funders has become essential for NGO survival in competitive environments (Carman \& Fredericks, 2010; Cousins, Goh, Elliott, \& Bourgeois, 2014; McCoy, Rose, \& Connolly, 2013). Increasingly, NGOs are embracing evaluation's potential as a vehicle for accountability and program improvement (Alaimo, 2008; Moxham, 2014). This need for information necessitates increased focus on organizational evaluation literacy for NGOs' ongoing sustainability.

In this paper, we hope to stimulate a wider conversation and further advance understanding of evaluation literacy by exploring the role of evaluation literacy in internal evaluation in the non-government sector. First, we review the relevant literature on evaluation use, internal evaluation, and evaluation literacy. Second, we present three Australian internal evaluator auto-narratives based on an exploratory exercise to reveal our experiences of internal evaluation practice. Third, we discuss the analysis from the narratives to reveal the underlying issues affecting evaluation use and elucidate the subject from the perspective of practitioners.

This paper responds to calls for expanded research into internal evaluation perspectives (Baron, 2011; Mayne, 2014). NGOs are an appropriate and worthy 
setting to expand understanding of internal evaluation. The NGO sector is diverse and complex, with huge variations in purpose, members, income streams, governance structures, activities, advocacy goals, size, values, and operational mechanisms (Lyons, 2001). This large sector is under-researched and not well understood compared with government education and health organizations, or organizations in the private sector (May, 2012). This paper addresses a lack of peer-reviewed literature from the perspective of internal evaluators on practical approaches to incorporating evaluation into the organization, particularly in relation to NGOs (Carman, 2007; Sobeck \& Agius, 2007).

\section{EVALUATION USE AND INTERNAL EVALUATION}

Theories of evaluation use can assist in understanding the different ways in which NGO employees engage with evaluation. Evaluation use is typically split into findings use and process use (Alkin \& Taut, 2003). The literature identifies three main types of findings use: instrumental, conceptual, and symbolic (Kirkhart, 2000). Findings use refers to use of the final results, judgments, and recommendations arising from an evaluation. Instrumental use is the most obvious of the three main types of findings use as it relates to uptake of evaluation recommendations and use of findings (Vo, 2015). Conceptual use refers to a subtle process whereby knowledge gained from multiple evaluations accumulates over months or years to change opinions, deepen understanding, and influence decision making in conscious and subconscious ways (Weiss, 2000). Finally, symbolic use relates to occasions when evaluation findings are used to bolster and provide legitimacy for decisions (Kirkhart, 2000).

While findings use is often the most obvious type of utilization considered, process use is gaining increasing prominence in the evaluation literature. Patton (2008) defines process use as "individual changes in thinking and behavior that occur among those involved in the evaluation as a result of the learning that occurs during the evaluation process" (p. 155). Researchers have found that engaging people in evaluation processes enhances the organizational capacity for evaluation and organizational learning (Amo \& Cousins, 2007; Owen \& Lambert, 1995; Preskill \& Torres, 2000). An extension of this is undertaking an intentional evaluation capacity building approach to systematically embed processes "for bringing about and sustaining a state of affairs in which quality program evaluation and its appropriate uses are ordinary and ongoing practices" (Stockdill, Baizerman, \& Compton, 2002, p. 8). Employees in NGOs could engage with evaluation through findings use or process use or intentional evaluation capacity building initiatives; these elements of use are interlinked.

Leviton (2014) suggests, beyond accountability, that organizational members can have difficulty visualizing the benefits and usefulness of evaluation. However, internal evaluators understand the values of the organization and can align the 
value proposition of evaluation with the specific context at that moment in time (Leviton, 2014). Volkov (2011b) defines internal evaluation as

a comprehensive and context-dependent system of intraorganizational processes and resources for implementing and promoting evaluation activities for the purposes of generating credible and practical knowledge to inform decision making, to make judgments about and improve programs and policies, and to influence organizational learning and decision-making behavior. (p. 27)

Baron (2011) considers an internal evaluator to be "an employee of the organization who performs evaluation functions to any degree-whether alone or in conjunction with other duties and responsibilities" (p. 88). The internal evaluator role requires knowledge and skills in evaluation and an understanding of organizational context in combination with responsiveness, flexibility, and creativity (Volkov, 2011b). Volkov (2011b) identifies the essential roles of the internal evaluator as change agent, educator about evaluation, evaluation capacity building practitioner, decision-making supporter, consultant, researcher, advocate, and organizational learning supporter. The internal evaluator is responsible for balancing these roles and navigating an appropriate path relevant to context: knowing when to step up, step in, and step back (Rogers, Bower, Malla, Manhire, \& Rhodes, 2017). Volkov and Baron (2011) highlight the importance of flexibility to enable internal evaluators to adapt to the demands of a changing society by promoting self-reflection and learning at the organizational level. They suggest that the "role of the internal evaluator will progressively change and expand, and promoting evaluative thinking throughout the entire organization will constitute one of the highly challenging and gratifying roles for the internal evaluators" (p. 106).

Internal evaluators are therefore linked to the concept of organizational learning and capacity building (Sonnichsen, 2000): their unique location as colleagues means they have increased opportunities to advocate for and facilitate change (Fleischer \& Christie, 2009; Love, 1991; Mathison, 2011; Sonnichsen, 2000). In conversation with Volkov (2011a), Arnold J. Love, a leading researcher on internal evaluation, reflected on how a utilization focus has signified a major change in values for internal evaluators, contrasting with the technical or methods-based approach favoured since the 1980s. Love (cited in Volkov, 2011a) states,

With a little, tiny program, you do not need to foist a massive evaluation design on people. Internal evaluators try very hard to work with program people rather than against program people, share the values that the people running the programs have, and also respect them and their information needs. (p. 11)

Smaller organizations do not necessarily have the resources to have an evaluation unit or designated evaluation position, but instead an evaluation function might be assigned as part of another role (Bourgeois \& Cousins, 2013). In NGOs, evaluation tasks are often undertaken by internal staff in addition to their other responsibilities (Carman, 2007; Stockdill et al., 2002). Bourgeois and Cousins 
(2013) recognize this as a potential advantage: "One can imagine process use being higher in such instances, since evaluation would be more integrated into the organizational decision-making function" (p. 314).

\section{EVALUATION LITERACY}

Bourgeois and Cousins (2008) propose that evaluation literacy is essential for organizations embedding evaluation and suggest that it can be increased by encouraging discussions about values and achievements and teaching about evaluation. Brady, Canavan, and Redmond (2016) highlight the importance of evaluation and research literacy to help staff with program development and interpretation of evaluation findings. Additionally, evaluation literacy helps increase the utilization of evaluation findings and of learnings from the process of evaluation (Brady et al., 2016).

Doherty, Eccleston, Hansen, Natalier, and Churchill (2015) claim that "evaluation literacy is what is really needed [in NGO settings] - the capacity to understand and use evaluation, not necessarily the capacity to do evaluation" (p. 36). This suggests that the organizational evaluation capacity to initiate, sustain, and use evaluation is independent from the capacity to conduct evaluation. Bourgeois, Whynot, and Thériault (2015) demonstrated application of their organizational evaluation capacity instrument in NGO settings and "found that capacity to use does not first require capacity to do" (p. 47). Therefore, evaluation literacy can be developed both prior to involvement with evaluation and as a result of involvement. However, before considering what this resembles in practice, a more indepth understanding of evaluation literacy from the literature is beneficial.

An early reference to evaluation literacy is Milstein and Wetterhall's (2000) article, which provides public-health practitioners with a framework for building evaluation literacy and competency by illustrating the steps involved and standards for evaluation practice. Their aim is to make evaluation more understandable and accessible by developing a practical tool to help practitioners use evaluation to its full potential. This was followed in 2002 by a drive to increase evaluation literacy and promote program evaluation among public-health practitioners (Milstein, Chapel, Wetterhall, \& Cotton, 2002). Evaluation capacity building literacy is understood by Baizerman, Compton and Stockdill (2002) to be "more or less explicit ways of reading and acting at the site so as to bring about, sustain, and manage ongoing quality program evaluation and its uses" (p. 112). Similarly, in the education sector, Nevo $(2001,2002)$ discusses the possibility of organizations increasing their institutional evaluation literacy through the practice of conducting evaluation internally.

Despite these early mentions, the move toward defining evaluation literacy did not really start until the focus on organizational evaluation capacity increased. Bourgeois' (2008) doctoral thesis defines evaluation literacy as "the extent to which organizational members are familiar with evaluation principles and practices" (p. 81). A special issue of the Canadian Journal of Program Evaluation in 2008 
focuses on organizational capacity for evaluation. The issue introduces evaluation literacy as a dimension of utilization, referring "to the broad knowledge of evaluation across the organization. It assumes increased knowledge eventually leads to increased use and thus refers to the extent to which an organization has a results-management orientation and whether other organizational members are encouraged to be involved in evaluation" (Bourgeois \& Cousins, 2008, p. 137). Subsequently, an organizational evaluation capacity instrument was developed that included evaluation literacy as a dimension of the capacity to use evaluation (Bourgeois, Toews, Whynot, \& Lamarche, 2013).

King (2017) suggests that evaluation literacy needs to be more clearly defined. While literature on evaluation provides a good basis to define evaluation literacy, this can be augmented by considering research on health literacy. Health literacy is defined as the way in which health services support individuals to be motivated and engage with health information. The World Health Organization (WHO, 1998) describes health literacy as "the cognitive and social skills which determine the motivation and ability of individuals to gain access to, understand and use information in ways which promote and maintain good health" (p. 10). We have combined the Bourgeois (2008) and WHO (1998) definitions to propose a new definition. Evaluation literacy is the cognitive and social skills that determine the motivation and ability of individuals to gain access to, understand, and use evaluative information in ways that ultimately contribute to achieving organizational goals. Acknowledging contextual and structural factors, individuals promoting and maintaining evaluation use can make a contribution to achieving organizational goals. This definition refers to evaluation literacy in the broadest possible sense. It encompasses access to all types of evaluation information from all stages of any evaluation process so that individuals are empowered to understand and use it effectively (Bourgeois, 2008; WHO, 1998).

Having reviewed and documented the relevant literature, we sought to do this exploratory exercise in order to reveal our own experiences of internal evaluation practice and, as a result, elucidate the subject from the perspective of practitioners.

\section{METHODS}

We are all currently undertaking doctoral-level research around topics that relate to internal evaluation. Each research project is different and focuses on distinct areas within this overarching topic. However, we are all studying and working in the NGO sector simultaneously and are seeking to ensure that our work will be useful and relevant for practitioners. Following a chance meeting at a conference where we all presented on different topics that had similar themes around promoting evaluation use with colleagues, we began discussing our roles. A formal exercise was then initiated by asking each other, "what is the role of evaluation literacy in internal evaluation in the non-government sector?"

Given that little has been documented about evaluation literacy from the internal perspective, we deem an appropriate method to address this question is 
through using a qualitative research approach, specifically by undertaking narrative inquiry. Clandinin and Connelly (2004) propose that narrative inquiry is a "multi-dimensional exploration of experience involving temporality (past, present, and future), interaction (personal and social), and location (place)" (p. 576). We utilize a narrative inquiry in combination with an autoethnographic approach to study ourselves and unpack our practice, documenting findings in auto-narratives. Clandinin and Connelly suggest that this type of individual study can assist with positioning the personal within the social-linking self-study to professional knowledge and revealing information about the context. Auto-narratives enable deep investigation and thick description of our unique individual experiences.

We wrote the auto-narratives separately using a series of sub-questions to guide the overarching direction: (1) What was the underlying issue in relation to evaluation use? (2) What skills were required to motivate and enable others to access, understand, and use evaluation information? (3) How did developing evaluation literacy relate to evaluation use? (4) How do internal evaluators continue to develop their own evaluation literacy? Initial analysis was conducted by the lead author. The narratives were read and searched for themes and points of relevance. Commonalities and differences were specifically noted if they appeared across all three of the auto-narratives. The coded summary that was specifically related to answering the sub-questions was then shared with the other authors to seek input, identify gaps, and come to agreement on interpretation. Analyzing interpretive biographies can focus on the career, role, or function as the unit of analysis to focus the findings (Coffey \& Atkinson, 1996). In this exercise, coding against the sub-questions focused the analysis on the role of evaluation literacy as the function or unit of analysis being studied. With the acknowledgement that the auto-narratives place our experiences within different social settings, the summaries also considered both individual and structural factors, as suggested appropriate for analyzing narratives related to career trajectories (Coffey \& Atkinson, 1996).

As internal evaluators working in three different Australian NGOs, we recognize the importance of using our position and skills to promote the use of evaluation to meet these multiple demands for information. Current literature on internal evaluation units reveals little about how this can be achieved in practice. This is affirmed by Olejniczak, Raimondo, and Kupiec (2016) who state, "The current evaluation literature does not explain well the reality of evaluation use in complex program and institutional settings" (p. 169). This research responds to the suggestion that the role of internal evaluation in developing enhanced evaluation use could be better articulated by exploring the connections between promoting evaluation use and the concept of evaluation literacy. Using autonarrative examples that focus on the importance of evaluation literacy from our three internal evaluation experiences, we attempt to initiate a discussion on evaluation literacy and respond to calls for expanded research into organizational attitudes toward evaluation and internal evaluation perspectives (Baron, 2011; Labin, Duffy, Meyers, Wandersman, \& Lesesne, 2012; Mayne, 2014). 
Our professional backgrounds are different. Public health nutrition, community development, and social work, for narratives one, two, and three respectively, provide us with very different undergraduate education and practical experiences. We have worked as evaluators in a range of NGOs. The narratives do not necessarily relate to our current roles but to the role we believe best highlights the varied experience of developing evaluation literacy in non-government settings. We have never worked together and, while our backgrounds are all in human service NGOs, our work settings cover a broad spectrum of the sector, encompassing family services, mental health, anti-trafficking, housing, and Indigenous health. These auto-narrative examples focus on NGOs providing social programs.

\section{FINDINGS}

Our three internal evaluation narratives highlight some of the challenges and solutions to enhancing evaluation literacy. They link practice with the theoretical constructs discussed above. The narratives provide personal examples of how the motivation and ability of organizational members to gain access to, understand, and use evaluative information was increased.

\section{Narrative 1: from a public health nutritionist}

I experienced a steep learning curve to develop my own evaluation literacy skills when I stepped into an internal evaluation role. I felt daunted by a formal monitoring, evaluation and learning position even though I had previously facilitated participatory engagement strategies and evaluated health promotion programs through my career in public health nutrition.

I seized any opportunity to work with external evaluators and be mentored in the craft of evaluation. Incorporating additional time into the contracts of commissioned evaluators for co-developing data collection tools, asking them to explain how they analyzed the data and listening to the tips and tricks of the trade, acting as critical friends, was invaluable. Coaching opportunities were practical periods of learning, but they were not enough. I joined the jurisdictional branch of the evaluation society and participated in networking events. I attended all the workshops, seminars, journal clubs and social networking events available. As co-convenor of the branch for over six years I played host to evaluators visiting from interstate and internationally. Formal post graduate studies at the masters level in evaluation also assisted in making me feel more secure about "owning" the position.

Yet the niggle of insecurity was never fully extinguished. I had not developed expertise in any one area. Exposure to the myriad of options for undertaking evaluation often left me more confused and uncertain. Engaging multiple external evaluators as critical friends left me with multiple perspectives who ardently believed their method was the right method. The more knowledge I gained about evaluation, the more unsure I felt about even calling myself an "internal evaluator." Surely there must be someone out there who would know how to do this job properly.

This inner turmoil was in stark contrast to the feedback I received from colleagues, executive management and the board. In contrast to the situation prior to commencing in the role, management was pleased with the way evaluation findings 
were being communicated, opportunities for learning were being incorporated and the data being made available. As a consequence, the human and financial resources dedicated to evaluation increased three-fold in as many years.

Volkov's (2011b) model for internal evaluator roles resonated strongly. I could see myself in that article and I found great consolation in knowing multiplicity was a strength. Volkov's article, in combination with an increased understanding of evaluation literacy, was the first step on a journey to reconciling my professional angst. I gained evaluation literacy through my studies and interactions. Examples included: knowing the difference between evaluation approaches so I could commission an evaluator with the right skill set; understanding the debate around bias and objectivity so I could advise when it would be appropriate for the organization to conduct an internal evaluation or an external evaluation; knowing where to source the tools and templates to assist with a particular request; facilitating participatory methods for developing criteria upon which we could collectively make evaluative judgements; developing project logic with teams; understanding how to adapt the presentation and communication of findings to suit the audience. I applied my generalist high-level evaluation literacy skills in many ways.

The real joy came through developing the evaluation literacy of others in the team. Formally, I implemented an intentional evaluation capacity building approach. To ascertain what was required to embed evaluative thinking into processes and make evaluation an integral efficient part of routine operations, a readiness appraisal was undertaken. I adopted a proactive approach to support my colleagues, as opposed to a reactive role, because of the framework we had developed through this participatory process.

Informally, I encouraged discussions about evaluation and stealthily negotiated how evaluation could be embedded using the art of gentle persuasion. Taking a longterm approach to identify the right moments in time for action and capitalize on appropriate learning styles was important. Using humour and social situations to help team members relax and find their own success was also essential. For example, when it was time to undertake some of the more mundane reporting requirements for head office, we'd say "Ah! Time to feed the hungry beast again!" This placed administrative monitoring in its place without detracting from the teams' quest to find answers to evaluative questions. In essence, making connections with colleagues to capitalize on interest and find the "win-win" situations was crucial for building momentum for embedding evaluation across the organization.

Increasing the focus on evaluation literacy, recognizing the multiplicity of roles required and highlighting the benefits of being a generalist, are all very worthwhile pursuits for an internal evaluator working in a non-government organization.

\section{Narrative 2: from a community development perspective}

My experience of evaluation has all been internal within small to medium sized NGOs. While this experience has varied considerably depending on the NGO, I am missing the experience that would come from being an external evaluator or even being an internal evaluator in a large NGO with an evaluation team. The most significant downfall of this has been the lack of mentorship and peer-review from other evaluators. I have been the only evaluator in each of my workplaces which has limited my ability to learn and develop my evaluation skills. To ameliorate these limitations, I have sought opportunities to network with evaluators in different organizations, 
attend evaluation focused conferences, read evaluation literature, and undertake postgraduate studies in evaluation.

I have found that my ideas of evaluation often clash with those advocated by some other evaluators, particularly those who unwaveringly believe in the quantitative "gold standard" and the axiomatic wonder of the results and evidence agenda. In that, I have found validation in texts such as Guijt, Shutt, Eyben, and Roche's (2015) important book The Politics of evidence and results in international development: Playing the game to change the rules? I question the usability and relevance of much evaluation practice and debate its ability to be transformative and stimulate change. My background in international and community development has a strong influence on my evaluation practice, underpinning my role as an internal evaluator with community development principles that reinforce the importance of empowerment, context-sensitivity, social change, and sustainability (Kelly, 2016a). While community development workers operate in different settings, maybe in a village with local residents, the philosophy and underpinning principles are highly relevant to my practice. My village is the NGO and the locals are my work colleagues.

In the early days of my work as an internal evaluator I experienced the frustration of evaluation non-use. My first program evaluation was difficult and time consuming. It involved collecting data in a fragile context from respondents suffering multiple forms of trauma and harbouring intense suspicion of outsiders. The eventual report was well praised by management and even earned me an "employee of the month" bottle of wine. My elation at recognition of the report's importance was quickly crushed as I watched the report being filed away, never to see the light of day again. It had fulfilled its duty as the mandated annual internal evaluation simply through its existence.

This momentary down point in my career catalyzed influential and ongoing selfreflection of my practice. It has made me an ardent follower of Michael Quinn Patton, particularly his Utilization-focused evaluation (2008). I recognized the immense waste of time and poor custodianship of respondents' stories my first evaluation epitomized. Clarity in my practice continues to develop over time. However, I am increasingly moving towards incorporation of community development principles in building evaluation literacy and promoting evaluation use. In my experience, the more formalized, standardized, and structured the evaluation, the less it resonates with NGO staff and impactees who could use it for transformative change. A formal evaluation is likely to have more effect on funders than an informal evaluation and so the need for formalized evaluation is still strong and continues to represent a large portion of my role. Rather than focus this section on formalized evaluation which may be conducted to "prove" a program's efficacy, I will focus on the more organic and reflective forms of evaluation which have been the most effective at developing evaluation literacy among my colleagues.

Despite involvement of program facilitators in formal evaluation processes, my colleagues have always been somewhat detached from evaluation results in formal report form. They may respond to the report and mention that it was interesting or that it was good to receive confirmation that what they are doing works, but they rarely change practice as a result of an evaluation. Recognizing that more formalized evaluation processes are not enough in themselves, we have worked to develop evaluation literacy through deliberate continuous implementation of informal discussions, storytelling, and reflective circles. My physical place in the team is important as I sit 
among the direct program delivery workers, not in a distant office or separate location. I am there on an ongoing basis, ubiquitously filling the office environment with evaluative questions and thoughts. The word "evaluation" is not used in instances where it might cause suspicion and anxiety; although it can be introduced when confidence has been increased. We review, reflect, and respectfully challenge. We talk about what change we want to make in people's lives, how we would want to be treated if we were accessing our programs, and what long term outcomes and impacts we are seeking to realize. We discuss terminology at length, drawing on Foucault's (2013) discourse analysis in particular. We reflect on what words mean and how words are loaded with connotations that affect our practice and the outcomes of recipients (Kelly, 2016b). This has resulted in significant shifts in practice such as team movement away from case managers managing cases to family services workers working with families.

As evaluators we can make space for evaluative discourses, but we cannot own them if we want them to be adopted and embedded by those involved. We can encourage evaluation literacy, quietly slip ideas into conversation and ask questions to stimulate reflections, but we cannot overtly lead these movements. While evaluators require strong skills as outlined in the evaluator competencies of each international and regional society, these skills must be coupled with an ability to engage with people at their level and not act within ivory towers. Rather than being seen the expert evaluator, I see the skills required for building evaluation literacy as the ability to facilitate without leading, to inspire conversation without dominating, and to encourage reflection without dictating. This includes the ability to hear everyone involved, not just those with the loudest voices. This is a messier way of working than the structured, logical, and controlled role of a traditional evaluator. The evaluator operating within this community development, non-directive leadership inspired framework is not revered as an expert and they do not hold ownership over judgements and recommendations. Instead they are humble facilitators of evaluation discourse who champion evaluation literacy in a way that aims to engender deep and embedded transformation of mindset, thought and practice.

\section{Narrative 3: from a social worker}

Like so many others, my foray into evaluation was rather serendipitous. I was recommended for a job by one of my university professors, and this saw me finally take the leap in moving away from a clinical social work role, towards a role in research and evaluation. The research part I was familiar with, but the evaluation part was mostly a mystery. I found myself on a steep learning curve, and as I reflect on those first 6 to 12 months as I write this today, I realize how steep in fact it was.

I was the first research and evaluation professional that this organization had and I remember being treated, not with suspicion, but certainly with a high level of interest and a bit of confusion. Breaking the news that I was a social worker and understood what it took to work at the frontline helped immensely in breaking down this early barrier and relieving some of the anxiety that may have existed around the role.

I soon found that working as an internal evaluator was indeed about breaking down barriers. And there were many. I didn't think about evaluation literacy in those early days, at least not directly, but I now realize that many of the difficulties I faced in introducing evaluation to the organization and having it make a meaningful contribution, were most likely hampered by a general lack of evaluation literacy. Back then, I would have made assumptions about why some colleagues appreciated 
evaluation and others didn't, but now that I think about it, was one person's poor attitude towards contributing to evaluation in their program, more an issue of understanding how evaluation can be used? Did another person's issue with evaluation more stem from a lack of understanding about what the purpose of evaluation was?

Those early years of implementing evaluation into the organization were very organic. However, eventually I took a shine to the evaluation capacity building literature - in particular, the work of Hallie Preskill and Rosalie Torres-and I developed a multitude of frameworks, processes and tools, with the aim of building evaluation capacity across all facets of the organisation (Preskill \& Boyle, 2008; Preskill \& Torres, 2000). These things are important; however in hindsight, when it comes to building evaluation literacy, the internal evaluator needs to find the right time to introduce them. Keeping a finger on the organizational pulse is another example of the "art" of internal evaluation. I realized very quickly that relationship-building was paramount in building a strong organizational culture for evaluation and focused my attention on this as much as possible. This included taking time to building rapport with frontline staff, middle management, and senior management. I grasped opportunities to speak with colleagues about evaluation: what it was, how it worked, and how it could contribute to achieving outcomes for clients, and ultimately the organizational mission. I was told by some that my passion for the subject was infectious.

I recognized some colleagues as evaluation champions (knowing in some cases, that their influence in building evaluation literacy would be greater than mine), and paid attention to identify those who were not. I acted with discretion and while I certainly did not "abandon" the latter group, I realized that with limited resources (for many years I was a sole internal evaluator), my energies needed to be targeted strategically. I found that most of my colleagues were willing to engage with evaluation. They knew a little and were happy to learn more-and I found great joy and satisfaction in working alongside these colleagues, sometimes to the point where they too became evaluation champions.

At first, as an early-career evaluator (and even now as a mid-career evaluator), I was very aware that I was on an evaluation journey of my own, and as I was building my evaluation knowledge and skills, I was attempting to build evaluation literacy in others. I was very conscious of what I didn't know; the more I read about evaluation, the more complex I understood it to be. While one might think that this is a "better than nothing" scenario, I now think that introducing and building evaluation literacy in an organization comes with great responsibility; having an evaluator with a solid comprehension of evaluation who can integrate that into a service delivery context with meaning and purpose, is critical. Over the years, my appreciation of the unique role of internal evaluators has grown, and I believe that they have a responsibility to build evaluation literacy as a key priority. However, I think this is incredibly difficult to do. To be successful, internal evaluators need to approach their work holistically and with great consideration to the breadth and depth of their role. This includes paying due attention to the service delivery context, making a concerted effort to understand the reality of delivering programs and services in their organization, introducing and sustaining evaluation within her/his organization in a way that speaks to this context and reality, having a broad understanding of organizational strategy, planning and decision-making, being a champion for learning and critical reflection, and an advocate for the role evaluation can play in improving programs and ultimately achieving social impact. 


\section{EMERGENT CONCEPTS AND DISCUSSION}

This section contains the product of our joint thematic analysis of the narratives in relation to the literature. While the findings are not generalizable, they offer perspectives from three Australian NGOs to provide insight into what is occurring at a practice level. Underpinned by constructivist understandings of truth and the nature of evidence (Lincoln \& Guba, 1989), this paper accepts that our three examples present pieces of the whole picture and add to the discursive and dynamic story of evaluation literacy in NGOs.

Arriving at this point in our career from different professional backgrounds means that we come to evaluation from different paradigms that affect how we understand rigor, trustworthiness, relevance, and quality. We have worked for NGOs of various sizes, with the authors of narratives 1 and 3 having experience in large NGOs with funding for external evaluators and professional development, while the author of narrative 2 has worked in small and medium sized NGOs. Additionally, while we are all currently undertaking doctoral degrees with a focus on evaluation, our previous exposure to tertiary evaluation training has varied, with the author of narrative 1 being the only author who has a postgraduate Master's qualification specifically focused on evaluation.

All three narratives follow a similar professional trajectory from practitioner to internal evaluator. The narratives explore the experience of travelling along a continuum whereby evaluation literacy is gradually built within ourselves as individuals, until the focus eventually becomes building the evaluation literacy of others. The narratives are framed within an overarching purpose of building evaluation capacity and embedding evaluation in the routine operations of the organization.

These auto-narratives highlight the importance of evaluation literacy, as they demonstrate the multiplicity of roles that internal evaluators play in building evaluation literacy to maximize the use of evaluation. The auto-narratives reveal some of the underlying issues affecting evaluation use in NGOs, such as findings not being communicated or used for decision making, opportunities for learning not being incorporated, evaluation reports not being appropriate for the target audience, and suspicion and anxiety being shown toward evaluation and its intended purpose. Internal evaluation practice therefore requires high-level cognitive and social skills to motivate and engage colleagues to access, understand, and use evaluation information. Humility, rapport building, passion, humour, persuasion, and overt and covert facilitation and persuasive and influential communication were some of the interpersonal qualities noted in the narratives.

The auto-narratives explore the ways in which we developed our own evaluation literacy; we engaged with external expertise and sought out theoretical knowledge and practical experience from a wide range of sources. This change in evaluation literacy enhanced organizational literacy, organizational evaluation cultures, and evaluation usage. This was achieved by taking opportunities to demonstrate how evaluation can contribute to achieving the organizational mission, using participatory approaches to bring the team along on the problem-solving 
journey and focusing on both the process and the outcomes as a means to improving the situation for beneficiaries.

Evaluation literacy is an essential component of embedding evaluation into organizational cultures, particularly in the non-government sector because of the many confounding contextual factors that heighten complexity. This is because internal evaluators are in a position to "understand how to integrate evaluation into programs and staff development in a way that reinforces the importance of evaluation, contributes to its habituation, but at the same time prevents its harmful routinization (senseless, repetitive use of the same techniques or instruments)" (Volkov, 2011b, p. 38).

However, it is not just about having certain qualities or skills as individual internal evaluators; it is about bringing other people along on the evaluation journey. Bourgeois (2016) states that the "overall evaluation literacy of organizational members, and especially of program managers, is considered to be an essential component of evaluation capacity" (p. 15). This is apparent in the auto-narratives, which demonstrate that internal evaluators are in an ideal position within organizations to influence this situation. As the definition of evaluation literacy implies, it is about the motivation and ability of everyone in the workplace to gain access to, understand, and use evaluative information (Bourgeois, 2008; WHO, 1998). As the narratives exemplify, this was achieved by ensuring that the focus on evaluation was linked to achieving the organizational mission and improving the lives of people accessing the programs. Participatory approaches that brought stakeholders together to strengthen and improve programs were key.

The auto-narratives resonate with Volkov's (2011b) call for internal evaluators to assist organizations to adopt evaluative thinking as a process, mindset, and capacity and to reorient organizations toward utilizing evaluation. With strong potential for evaluative thinking to become embedded into routine operations, internal evaluators are in a good position to identify strategies that are more likely to be successful in their specific context, as noted in the narratives.

Although the focus for an internal evaluator may be on building the evaluation literacy of team members across the organization, as these narratives demonstrate, self-reflection and self-assessment are integral parts of the mindset of internal evaluators intent on building their own evaluation capacity. A consistent theme is that all three of us are acutely aware of what we do not know and how much more there is to learn. Rather than being overwhelmed by this, we rise to the challenge and see evaluation literacy as a journey of lifelong learning. We do not let this become a paralyzing situation. The narratives illustrate that we reflect upon the complexity and continue to strive toward developing our own evaluation literacy as well as that of our colleagues.

We emphasize cognitive and social skills in the evaluation literacy definition because of the high-level communication and interpersonal skills required to promote evaluation use. King (2016) highlights the importance of purposefully structuring interactions with the people who will use the evaluation to assist them in understanding the results and ensure that recommendations are reasonable and 
relevant. In relation to understanding and use, King (2016) states, "Get personal because, perhaps most fundamentally, successful evaluation practice builds on personal relationships" (p. 9). This resonates strongly with Patton's (2008) focus on the vital importance of the personal factor: the "presence of an identifiable individual or group of people who personally care about the evaluation and the findings it generates" (p. 66). Each of the narratives addresses the close relationships we have with our colleagues and the importance of this. Narrative 1 highlights the importance of relaxing anxiety surrounding evaluation by generating humour around demands. Narrative 2 suggests that internal evaluators physically sit among their colleagues to strengthen organizational rapport, which results in enhanced evaluation embeddedness. Narrative 3 discusses how it was helpful to break the initial perceived barrier between her as an evaluator and the rest of the team by explaining her grounding in social-work practice. All three narratives demonstrate that internal evaluators have multiple opportunities to capitalize on the interpersonal dynamics within a workplace to develop the evaluation literacy of team members and thus increase organizational evaluation capacity.

\section{CONCLUSION}

This paper has attempted to add to the understanding of evaluation literacy and progress toward a clear definition of evaluation literacy as the cognitive and social skills that determine the motivation and ability of individuals to gain access to, understand, and use evaluative information in ways that contribute to achieving organizational goals. Avoiding a narrow definition, we suggest that evaluation literacy should be understood in the broadest possible sense. This definition encompasses access to evaluation information so that individuals are empowered to understand and use evaluation in ways that are appropriate and meaningful for their context.

Evaluation in non-government organizations is a complex undertaking. Without making broad generalizations, we propose that the auto-narratives offer insight into the challenges facing internal evaluators in Australian NGOs and how evaluation literacy can be enhanced. Key barriers facing evaluation literacy in NGOs are identified in the narratives as a lack of money to invest in professional development, a general lack of clarity around what evaluation literacy is, and a lack of mentorship for internal evaluators in smaller NGOs. While some challenges were identified, the auto-narratives demonstrate a number of ideas for increasing evaluation literacy. These include using external evaluators as critical friends, undertaking tertiary training in evaluation, building strong rapport with organizational staff, maintaining a reflective mindset, and seeking to diminish evaluation anxiety through engaging with staff as peers and using humour.

For evaluation to find its optimal role in the sector, it needs to become the responsibility of many. The tertiary education sector can better equip humanservices graduates for evaluation. Community organizations can see evaluation as an investment and strengthen their use of it to improve the programs they deliver. 
Sector and organizational leaders can better advocate for the role of evaluation. Human-service practitioners can strengthen their understanding of evaluation as it relates to evidence-informed practice. And evaluators, whether internal or external, can do more to make evaluation literacy a priority in their practice. NGOs that have an evaluation literate workforce, who use the most appropriate form of evaluation at the right time and who are assisted by internal evaluators to enhance evaluative thinking and critical reflection, have an increased likelihood of achieving the greatest social impact.

\section{ORCID iDS}

Alison Rogers (D) http://orcid.org/0000-0003-3201-9382

Leanne M. Kelly (D http://orcid.org/0000-0002-3360-5212

Alicia McCoy (Dttps://orcid.org/0000-0002-3811-4551

\section{REFERENCES}

Alaimo, S. P. (2008). Nonprofits and evaluation: Managing expectations from the leader's perspective. New Directions for Evaluation, 119(Fall), 73-92. https://doi.org/10.1002/ ev.269

Alkin, M. C., \& Taut, S. M. (2003). Unbundling evaluation use. Studies in Educational Evaluation, 29(1), 1-12. https://doi.org/10.1016/S0191-491X(03)90001-0

Amo, C., \& Cousins, J. B. (2007). Going through the process: An examination of the operationalization of process use in empirical research on evaluation. New Directions for Evaluation, 2007(116), 5-26. https://doi.org/10.1002/ev.240

Baizerman, M., Compton, D. W., \& Stockdill, S. H. (2002). New directions for ECB. New Directions for Evaluation, 2002(93), 109-120. https://doi.org/10.1002/ev.45

Baron, M. E. (2011). Designing internal evaluation for a small organization with limited resources. New Directions for Evaluation, 2011(132), 87-99. https://doi.org/10.1002/ ev.398

Bourgeois, I. (2008). Understanding the dimensions of organizational evaluation capacity (Doctoral dissertation). Faculty of Graduate and Postdoctoral Studies, University of Ottawa, ON, Canada. Retrieved from https://ruor.uottawa.ca/handle/10393/29565

Bourgeois, I. (2016). Performance measurement as precursor to organizational evaluation capacity building. Evaluation Journal of Australasia, 16(1), 11. https://doi.org/10.117 7/1035719X1601600103

Bourgeois, I., \& Cousins, J. B. (2008). Informing evaluation capacity building through profiling organizational capacity for evaluation: An empirical examination of four Canadian federal government organizations. Canadian Journal of Program Evaluation, 23(3), 127.

Bourgeois, I., \& Cousins, J. B. (2013). Understanding dimensions of organizational evaluation capacity. American Journal of Evaluation, 3(34), 299-319. https://doi. org/10.1177/1098214013477235 
Bourgeois, I., Toews, E., Whynot, J., \& Lamarche, M. K. (2013). Measuring organizational evaluation capacity in the Canadian federal government. Canadian Journal of Program Evaluation, 28(2).

Bourgeois, I., Whynot, J., \& Thériault, E. (2015). Application of an organizational evaluation capacity self-assessment instrument to different organizations: Similarities and lessons learned. Evaluation and Program Planning, 50, 47-55. https://doi.org/10.1016/j. evalprogplan.2015.01.004. Medline:25757074

Brady, B., Canavan, J., \& Redmond, S. (2016). Bridging the gap: Using Veerman and Van Yperen's (2007) framework to conceptualise and develop evidence informed practice in an Irish youth work organisation. Evaluation and Program Planning, 55, 128-133. https://doi.org/10.1016/j.evalprogplan.2016.01.003 . Medline:26844427

Braverman, M. T. (2013). Negotiating measurement: Methodological and interpersonal considerations in the choice and interpretation of instruments. American Journal of Evaluation, 34(1), 99-114. https://doi.org/10.1177/1098214012460565

Campbell, D. A., Lambright, K. T., \& Bronstein, L. R. (2012). In the eyes of the beholders. Public Performance \& Management Review, 36(1), 7-30.

Carman, J. G. (2007). Evaluation practice among community-based organizations: Research into the reality. American Journal of Evaluation, 28(1), 60-75. https://doi. org/10.1177/1098214006296245

Carman, J. G., \& Fredericks, K. A. (2010). Evaluation capacity and nonprofit organizations: Is the glass half-empty or half-full? American Journal of Evaluation, 31(1), 84-104. https://doi.org/10.1177/1098214009352361

Clandinin, D. J., \& Connelly, M. (2004). Knowledge, narrative and self-study. In J. J. Loughran, M. L. Hamilton, V. K. LaBoskey, \& T. Russell (Eds.), International handbook of self-study of teaching and teacher education practices. Springer International Handbooks of Education, Vol. 12. Dordrecht, Netherlands: Springer.

Coffey, A., \& Atkinson, P. (1996). Narratives and stories. In Making sense of qualitative data: Complementary research strategies (pp. 54-82). Thousand Oaks, CA: SAGE Publications.

Cousins, J. B., Goh, S. C., Elliott, C. J., \& Bourgeois, I. (2014). Framing the capacity to do and use evaluation. New Directions for Evaluation, 2014(141), 7-23. https://doi. org/10.1002/ev.20076

Doherty, B., Eccleston, R., Hansen, E., Natalier, K., \& Churchill, B. (2015). Building evaluation capacity in micro community organisations-more burden than benefit? Evaluation Journal of Australasia, 15(4), 29-37. https://doi.org/10.1177/10357 19X1501500404

Fleischer, D. N., \& Christie, C. A. (2009). Evaluation use: Results from a survey of U.S. American Evaluation Association members. American Journal of Evaluation, 30(2), 158-175. https://doi.org/10.1177/1098214008331009

Foucault, M. (2013). Archaeology of knowledge (2nd ed.). Hoboken, NJ: Taylor \& Francis.

Guijt, I., Shutt, C., Eyben, R., \& Roche, C. (2015). The politics of evidence and results in international development: Playing the game to change the rules? Rugby, England: Practical Action Publishing. 
Kelly, L. M. (2016a). Reflections of an evaluator navigating between community development and welfare paradigms. Development in Practice, 26(4), 517-521. https://doi.or g/10.1080/09614524.2016.1164123

Kelly, L. M. (2016b). Perceptions of poverty and the perpetuation of the capability-judgement cycle in outer southeast Melbourne. Community Development, 47(5), 584-601. https:// doi.org/10.1080/15575330.2016.1226913

King, J. A. (2016). Taking what action for change? Dare evaluation build a new social order? Visitor Studies, 19(1), 3-11. https://doi.org/10.1080/10645578.2016.1144022

King, J. A. (2017). Putting evaluation capacity building in context: Reflections on the Ontario Brain Institute's Evaluation Support Program. Evaluation and Program Planning. https://doi.org/10.1016/j.evalprogplan.2017.05.013. Medline:28641901

King, J. A., \& Volkov, B. B. (2005). A framework for building evaluation capacity based on the experiences of three organizations. CURA Reporter, 3(35), 10-16.

Kirkhart, K. E. (2000). Reconceptualizing evaluation use: An integrated theory of influence. New Directions for Evaluation, 2000(88), 5-23. https://doi.org/10.1002/ev.1188

Labin, S. N., Duffy, J. L., Meyers, D. C., Wandersman, A., \& Lesesne, C. A. (2012). A research synthesis of the evaluation capacity building literature. American Journal of Evaluation, 33(3). https://doi.org/10.1177/1098214011434608

Lee, C., \& Nowell, B. (2015). A framework for assessing the performance of nonprofit organizations. American Journal of Evaluation, 36(3), 299-319. https://doi. org/10.1177/1098214014545828

Leviton, L. C. (2014). Some underexamined aspects of evaluation capacity building. American Journal of Evaluation, 35(1), 90-94. https://doi.org/10.1177/1098214013502844

Lincoln, Y., \& Guba, E. (1989). Fourth generation evaluation. Newbury Park, CA: SAGE.

Love, A. J. (1991). Internal evaluation: Building organizations from within. Newbury Park, CA: SAGE.

Lyons, M. (2001). Third sector: The contribution of non-profit and cooperative enterprises in Australia. Sydney, Australia: Allen \& Unwin.

Mathison, S. (2011). Internal evaluation, historically speaking. New Directions for Evaluation, 2011(132), 13-23. https://doi.org/10.1002/ev.393

May, S. (2012). Case studies in organizational communication: Ethical perspectives and practices. Thousand Oaks, CA: SAGE.

Mayne, J. (2014). Issues in enhancing evaluation use. In M. Läubli Loud \& J. Mayne (Eds.), Enhancing evaluation use: Insights from internal evaluation units (pp. 1-14). Thousand Oaks, CA: SAGE.

McCoy, A., Rose, D., \& Connolly, M. (2013). Developing evaluation cultures in human service organisations. Evaluation Journal of Australasia, 13(1), 15. https://doi.org/10. 1177/1035719X1301300103

McCoy, A., Rose, D., \& Connolly, M. (2014). Approaches to evaluation in Australian child and family welfare organizations. Evaluation and Program Planning, 44, 68-74. https://doi.org/10.1016/j.evalprogplan.2014.02.004. Medline:24607886 
Milstein, B., Chapel, T. J., Wetterhall, S. F., \& Cotton, D. A. (2002). Building capacity for program evaluation at the Centers for Disease Control and Prevention. New Directions for Evaluation, 2002(93), 27-46. https://doi.org/10.1002/ev.40

Milstein, B., \& Wetterhall, S. (2000). A framework featuring steps and standards for program evaluation. Health Promotion Practice, 1(3), 221-228. https://doi. org/10.1177/152483990000100304

Moxham, C. (2014). Understanding third sector performance measurement system design: A literature review. International Journal of Productivity and Performance Management, 63(6), 704-726. https://doi.org/10.1108/IJPPM-08-2013-0143

Naccarella, L., Pirkis, J., Kohn, F., Morley, B., Burgess, P., \& Blashki, G. (2007). Building evaluation capacity: Definitional and practical implications from an Australian case study. Evaluation and Program Planning, 30(3), 231-236. https://doi.org/10.1016/j. evalprogplan.2007.05.001. Medline:17689328

Nevo, D. (2001). School evaluation: Internal or external? Studies in Educational Evaluation, 27(2), 95-106. https://doi.org/10.1016/S0191-491X(01)00016-5

Nevo, D. (2002). Dialogue evaluation: Combining internal and external evaluation. In School-based evaluation: An international perspective (Vol. 8, pp. 3-16). Bingley, England: Emerald Group.

Olejniczak, K., Raimondo, E., \& Kupiec, T. (2016). Evaluation units as knowledge brokers: Testing and calibrating an innovative framework. Evaluation, 22(2), 168. https://doi. org/10.1177/1356389016638752

Owen, J. M., \& Lambert, F. C. (1995). Roles for evaluation in learning organizations. Evaluation, 1(2), 237-250. https://doi.org/10.1177/135638909500100207

Patton, M. (2008). Utilization-focused evaluation. Thousand Oaks, CA: SAGE.

Preskill, H., \& Boyle, S. (2008). A multidisciplinary model of evaluation capacity building. American Journal of Evaluation, 29(4), 443-459. https://doi. org/10.1177/1098214008324182

Preskill, H., \& Torres, R. T. (2000). The learning dimension of evaluation use. New Directions for Evaluation, 2000(88), 25-37. https://doi.org/10.1002/ev.1189

Rogers, A., Bower, M., Malla, C., Manhire, S., \& Rhodes, D. (2017). Developing a cultural protocol for evaluation. Evaluation Journal of Australasia, 17(2), 11-19. https://doi.or g/10.1177/1035719X1701700203

Sobeck, J., \& Agius, E. (2007). Organizational capacity building: Addressing a research and practice gap. Evaluation and Program Planning, 30(3), 237-246. https://doi. org/10.1016/j.evalprogplan.2007.04.003. Medline:17689329

Sonnichsen, R. C. (2000). High impact internal evaluation: A practitioner's guide to evaluating and consulting inside organizations. Thousand Oaks, CA: SAGE.

Stockdill, S. H., Baizerman, M., \& Compton, D. W. (2002). Toward a definition of the ECB process: A conversation with the ECB literature. New Directions for Evaluation, 2002(93), 7-26. https://doi.org/10.1002/ev.39

Vo, A. (2015). Foreword. In C. Christie \& A. Vo (Eds.), Evaluation use and decision making in society: A tribute to Marvin C. Alkin (pp. vii-xviii). Charlotte, NC: Information Age Publishing. 
Volkov, B. B. (2011a). Internal evaluation a quarter-century later: A conversation with Arnold J. Love. New Directions for Evaluation, 2011(132), 5-12. https://doi.org/10.1002/ ev.392

Volkov, B. B. (2011b). Beyond being an evaluator: The multiplicity of roles of the internal evaluator. New Directions for Evaluation, 2011(132), 25-42. https://doi.org/10.1002/ ev.394

Volkov, B. B., \& Baron, M. E. (2011). Issues in internal evaluation: Implications for practice, training, and research. New Directions for Evaluation, 2011(132), 101-111. https://doi. org/10.1002/ev.399

Weiss, C. (2000). What we have learned from 25 years of knowledge utilization. In R. Henke (Ed.), Final report for the international conference on social science and governance: The linkage between social science research and social policy (pp. 20-21). Zeist, Netherlands: Netherlands Commission for UNESCO, Management of Social Transformations.

World Health Organisation (WHO). (1998). Health promotion glossary. Geneva, Switzerland. Retrieved from www.who.int/healthpromotion/about/HPR\%20Glossary\%20 1998.pdf

\section{AUTHOR INFORMATION}

Alison Rogers is a PhD candidate with the Centre for Program Evaluation at The University of Melbourne. She is also the Development Effectiveness Coordinator with the Indigenous Australia Program of The Fred Hollows Foundation based in Darwin, Northern Territory.

Leanne M. Kelly has been working as a practitioner, researcher, and evaluator in community development and social services NGOs for the past 15 years. She is currently undertaking PhD research on program evaluation in small NGOs through scholarship with the Alfred Deakin Institute at Deakin University in Geelong.

Alicia McCoy has a background in social work, research, and evaluation and is currently Head of Research and Evaluation at Beyond Blue, an independent, nonprofit organisation working to lower the prevalence and reduce the impact of depression, anxiety and suicide in Australia. Alicia has a PhD in evaluation from The University of Melbourne. 